\title{
EMS Systems: Foundations for the Future
}

\author{
ROBERT E. O'CONNOR, MD, MPH, DAVID C. CONE, MD, \\ ROBERT A. DE LORENZO, MD, ROBERT M. DOMEIER, MD, \\ WAYNe E. MOORE, MD, PETER P. TAILlaC, MD, \\ VINCENT P. VERDILE, MD, BRIAN S. ZACHARIAH, MD, \\ STEVEN J. DAVIDSON, MD
}

\begin{abstract}
Emergency medical services (EMS) occupy a unique position in the continuum of emergency health care delivery. The role of EMS personnel is expanding beyond their traditional identity as outof-hospital care providers, to include participation and active leadership in EMS administration, education, and research. With these roles come new challenges, as well as new responsibilities. This paper
\end{abstract}

was developed by the SAEM EMS Task Force and provides a discussion of these new concepts as well as recommendations for the specialty of emergency medicine to foster the continued development of all of the potentials of EMS. Key words: emergency medical services; EMS; future. ACADEMIC EMERGENCY MEDICINE 1999; 6:46-53
$\mathrm{T}$ HE PHRASE "health care reform" has achieved colloquial use since being prominently displayed in The President's Health Security $P l a n^{1}$ of 1993 . While the President's Blueprint has failed, health care reform proceeds unabated. Costcontainment pressures have assumed public roles, to the point where politicians and regulators have wrested control in medical decision making from practitioners. $^{2}$

The same forces reshaping health care are being imposed on emergency medical services (EMS). Managed care organizations have been accused of creating health care access systems in parallel with existing EMS services in hopes of limiting

From the Department of Emergency Medicine, Christiana Care Health System, Newark, DE (REO); Department of Emergency Medicine, Division of EMS, MCP-Hahnemann School of Medicine, Philadelphia, PA (DCC); Department of Medical Science, U.S. Army Academy of Health Sciences, Ft. Sam Houston, TX (RAD); Emergency Medicine Residency Program, University of Michigan/St. Joseph-Mercy Hospital, Ann Arbor, MI (RMD); District of Columbia Fire and Emergency Medical Services Department (WEM), Washington, DC; Department of Emergency Medicine, Pioneer Valley Hospital, West Valley, UT (PPT); Department of Emergency Medicine, Albany Medical College, Albany, NY (VPV); Department of Emergency Medicine, Division of EMS, University of Texas, Southwestern, Dallas, TX (BSZ); and Department of Emergency Medicine, Maimonides Medical Center, Brooklyn, NY (SJD).

Received March 2, 1998; revision received September 3, 1998; accepted September 15, 1998.

Approved by the SAEM Board of Directors March 13, 1998. Address for correspondence and reprints: Robert E. O'Connor, MD, MPH, Department of Emergency Medicine, Christiana Care Health System, 4755 Ogletown-Stanton Road, Newark, DE 19718. Fax: 302-733-1595; e-mail: roconnor@christianacare. org "unnecessary" ED use or, worse, imposing a form of economic discrimination. ${ }^{3,4}$ Consolidation of ambulance service has resulted from the wholesale acquisition of regional services by national corporations, whose power to shape future direction of EMS is formidable. These complex forces are acting on EMS in such a way that planning, adaptation, and innovation have become necessary to avoid disruptions in service. The intent of this paper is to outline a plan for education, research, and academic maturation to better integrate EMS systems with existing health care services.

\section{CONTEMPORARY GOALS OF EMS}

Traditionally, EMS has been viewed as beginning with activation by the initial call and ending with the transfer of care to the ED. Such a narrow view neglects the increasing importance of EMS involvement in events preceding the call, such as prevention, or subsequent to the call, such as rehabilitation., ${ }^{5,6}$ EMS does not exist to perform isolated interventions, but rather is one component of an integrated health care system.

There should be extensive coordination of efforts among EMS physicians, emergency physicians (EPs), out-of-hospital providers, and political coalitions in organizing, planning, implementing, and overseeing all aspects of the system. Such a system should provide for universal access, with safeguards in place to detect and eliminate fraud or abuse. Strategies to better integrate the unique requirements of managed care organizations with guaranteed response for all persons perceiving an immediate need for services must be developed. ${ }^{7,8}$ 
Fair reimbursement for appropriate services must be available to guarantee the financial survival of quality EMS organizations.

\section{ACCESS TO CARE}

Emergency medical services must promote a strong ethical foundation for providers, system designers, administrators, and medical directors. This foundation acknowledges that EMS systems have obligations both to the individual patient and to society as a whole. Call response must be timely and systems should be adequately staffed so that providers are not overburdened with excessive volume.

The benefit of EMS has been questioned..$^{9-11}$ Evaluation of services using traditional outcome measures may not be appropriate since EMS exists to provide access, stabilization, and transport. Such a service should not be assessed solely on the basis of clinical improvement during transport. An intact EMS system affords the public myriad benefits that cannot be easily measured by mortality, morbidity, or quality-of-life indicators.

A successful EMS system needs financial support by government, insurance companies, and/or managed care organizations. The challenge facing EMS is to accommodate consumer-driven demand for unscheduled services with efficiency and efficacy. ${ }^{10-14}$ Whether or not an emergency condition exists should be decided by the patient, or the party requesting assistance, and should not be questioned retrospectively, once the diagnosis is known. To deny care, require gatekeeper approval, or impose financial disincentives is to invite disaster should illness severity be underestimated. ${ }^{15}$ It is preferable to perform an initial evaluation and turn care over to a lower-level provider, than to force patients to self-triage. ${ }^{4}$

The use of copayments to deter "improper" utilization of EMS may be in conflict with the principle of universal access to care. Improper utilization is more properly addressed through the use of dispatch protocols, caller questioning, prearrival instructions, and medical direction to provide an appropriate response. ${ }^{16,17}$ EMS should respond to all legitimate calls for assistance regardless of ability to pay. The level of response [advanced life support (ALS), basic life support (BLS), lights and siren, etc.] should be guided by dispatch assessment.

\section{NONTRADITIONAL ROLES IN MEDICAL DIRECTION}

Physicians should have significant involvement in the education, training, protocol development, and supervision of all EMS providers. ${ }^{18}$ There should be a system for collecting data from out-of-hospital patient care records as well as from interrelated sources such as dispatch centers, police agencies, EDs, and hospitals. Data analysis is essential to gauge the appropriateness of care rendered but may also be required for financial oversight and directing public educational efforts for utilization and prevention. ${ }^{19}$ In addition to monitoring patient care, medical direction may be enhanced by attending to less traditional areas of funding, injury prevention, and provider well-being.

Research is essential for evidence-based decision making regarding trauma care, cardiac arrest, EMS for children, community health, and the assessment of new technology. Increased funding for research is an investment that will pay dividends in lives saved and increased efficiency. Research funding has been available in the past to assist with system improvement, data collection, trauma systems, pediatrics, and communications.

It is crucial for the EMS medical director to be aligned with the state EMS office to identify sources of funding and secure grants since sources may change frequently. Many federal grant programs, such as the Emergency Medical Services for Children (EMS-C) program and trauma systems development funds, rely on the state EMS office for application and disbursement. Other grant programs are available only through collaboration with the state office.

Injury prevention can be a cost-effective and vital public service provided by EMS through a combination of data collection, risk assessment, and public education. Promotional campaigns for bicycle helmets, seat belts, and household injury prevention have helped to reduce morbidity and mortality. EMS providers are distributed throughout the community, and are a formidable, although underutilized, resource in implementing prevention programs. Areas of development should include public education and risk recognition. EMS personnel have a unique insight into the living conditions and patterns of injury encountered in the community, and represent a tremendous resource for developing community-based prevention strategies. ${ }^{20}$ Successful community interventions are exemplified by the Pinellas County (FL) and Tucson (AZ) infant drowning prevention programs, where EMS personnel conducted educational programs for parents and pool owners, along with site surveys for pool safety. Each resulted in a dramatic reduction in unintentional childhood drowning. ${ }^{21,22}$

Emergency medical services personnel are an irreplaceable resource whose personal well-being is of paramount importance to effective patient care. Scene safety, occupational health hazards, unintentional injuries, and traumatic stress disorders are areas that should be continuously mon- 
itored and regulated by emergency medical oversight. EMS personnel should be provided with continuing medical education aimed at stress management and reducing occupational health hazards and unintentional injuries. Maintaining the mental and physical well-being is a desirable goal and should be a vested interest of all EMS providers.

\section{EMS MEDICAL LEADERSHIP DEVELOPMENT}

The majority of EPs have at least some interaction with EMS providers in offering medical direction. However, offering EMS medical direction for an individual patient encounter differs from the medical leadership role required of system medical direction. This leadership role requires that the physician work with an interdisciplinary team providing expertise in EMS system design, legislative and administrative requirements, and data collection needs. While EMS system medical direction is primarily clinical, acquisition of additional skills in such diverse areas as epidemiology, management, and business administration can be extremely useful. One word of caution is in order: do not abuse medical privilege. The EMS medical director should be wary of inappropriately invoking his or her medical authority to influence nonclinical decisions more appropriately handled in the context of administrative or fiscal decision-making.

Recognition of the unique blend of skills required in EMS may make advanced training enticing to the physician interested in leadership development. Residency training should be required, preferably in emergency medicine (EM). Fellowship training, often combined with an advanced degree in health care administration, public health, or business, is a means of training future leaders in EMS. Pursuing an advanced degree may be beneficial in that skills not commonly taught in medical education may be acquired. Course work in epidemiology, biostatistics, health services administration, accounting, finance, and research methods may be useful, especially if medical direction has administrative components. Continued refinement of the curriculum of the EMS fellowship is necessary to adapt to a changing health care environment. Physicians who complete fellowship training and dedicate their careers to EMS will become a vital force in shaping the future.

\section{EDUCATION}

Providers. Medical directors involved in the training of EMS providers should be proficient in adult education, especially if they are actively involved in curriculum design. Physician involve- ment in instructing and evaluating skills, particularly at the ALS level, is important. True understanding of the in-field aspects of EMS can be gained only by physician participation in field activities. The physician preceptor who has a working knowledge of street care can be extremely effective and credible. In addition, field precepting serves as an important means for evaluating the training received by the students, for this is where the sum of their training must be integrated to care for patients.

Emergency Medicine Residents. Surveys of EM residency programs have consistently demonstrated tremendous variability in the extent and scope of the EMS curriculum. Didactic teaching of the essential principles of EMS, as set forth in the EM core content, ${ }^{23}$ is fairly uniform. In contrast, experiential learning, field work, provider teaching, review activities, and advanced didactic training in EMS remain varied. ${ }^{24}$ Currently, there are few formal requirements for EMS experience during EM residency training. The degree of experiential training is most often decided by the program director at each institution.

Urban, suburban, and rural programs have completely different types of EMS systems to use for teaching. Centers differ in their access to such resources as air medical programs and active EMS research centers. Programs with fewer resources need to rely more heavily on didactic teaching, and should seek to establish relationships with outside resources to enhance their EMS curricula. EM residency program directors are encouraged to incorporate some EMS experience into their curricula to foster an appreciation for out-of-hospital patient care and to promote physician-provider interaction.

At present, every EM residency program in the United States offers an EMS rotation. ${ }^{24}$ Advanced electives, designed for residents with a particular interest in EMS, should be available to every EM resident. The educational rationale for making such electives available is to permit residents to gain experience in EMS leadership, enabling them to make more qualified career choices. EMS physicians should seek ways to increase resident participation in advanced-level activities, such as research, policy making, and disaster planning. ${ }^{25,26}$

EMS Fellows. A strong EMS presence within residency programs will help encourage participation in EMS fellowships. As the future leaders of academic EMS, fellows must become involved in all aspects of local, regional, and national EMS activities. Participation in national committee work, advanced research, and the study of recent developments in systems management concepts will 
help ensure a ready supply of academic leaders who can contribute enthusiasm, expertise, and innovation. EMS fellowship training should train physicians to oversee high-performance EMS systems.

The SAEM EMS Committee has developed a curriculum for EMS fellowships that sets a number of prerequisites for the fellow, the fellowship director, and the host institution. ${ }^{27}$ These standards are designed to help ensure that adequate resources are available to the fellow to maximize learning. A number of didactic goals are outlined, along with many experiential activities designed to prepare the fellow for active leadership in EMS. A number of fellowship programs combine EMS training with the opportunity to complete a master's in public health (MPH), master's in health services administration (MHSA), or other degree program. The MPH may focus on public health, epidemiology, or public health issues, while the master's in business administration (MBA) may emphasize cost-effectiveness research, and the master's in policy administration (MPA) may develop and explore public policy issues. Such diversity of expertise, research interest, and career focus can only benefit EMS, and enhance the academic credibility of EMS physicians.

EM Attending Physicians. Emergency physicians, in both the academic and community settings, should incorporate EMS into their continuing medical education (CME) regimen. Considering the rapid pace at which EMS technology, systems design, and quality issues are changing, it is essential for all EPs to maintain some degree of awareness of new developments. Physicians whose sole involvement with EMS is to provide on-line medical direction and receiving patients brought into the ED by EMS will find a need to remain current. The use of pneumatic antishock garments (PASGs), ${ }^{28}$ high-dose epinephrine for cardiac arrest, ${ }^{29}$ aggressive fluid resuscitation, ${ }^{30}$ and verification of endotracheal tube placement ${ }^{31,32}$ are examples of EMS issues affecting the practice of EM.

Nursing and Other Allied Medical Personnel. Other ED staff, including nurses, physician assistants, and nurse practitioners, also need continuing education in EMS. Interactions between allied staff and EMS providers are very important, particularly in the transfer of information from the field staff to the ED staff. EMS physicians should work to define the needs of these allied personnel, and implement methods for maintaining a patient care information database to facilitate a seamless transition of care from EMS to hospital. An up-todate knowledge of current EMS issues, as well as regularly updated information regarding the spe- cifics of the local EMS system, will help ensure useful and productive interactions.

Physicians in Other Specialties. Physicians in other specialties must be aware of the capabilities and limitations of the local EMS system serving their areas. EMS should include the community specialists in decision making in order to integrate state-of-the-art care into the community. Field triage to specialty care may become important for patients with stroke or acute myocardial infarction.

General practitioners, internists, and others involved in an office-based practice may need to summon EMS to provide treatment and transport to the hospital. Such physicians need to be aware of the type of response they can expect, the capabilities of responding providers, and local policies regarding medical control when a physician is on scene. These educational programs can be implemented through a variety of sources, including local, county, and state medical societies, hospital staff groups, and specialty societies.

The Public. Education of the public regarding EMS, including the first links of the "chain of survival," is the responsibility of physicians, administrators, and providers. Academic EMS physicians should lead the way in developing methods designed to enhance public knowledge of EMS and promote health awareness and prevention. Proper access to EMS, considering the possibilities of both over- and underutilization, is of paramount importance. ${ }^{4,7,8,11,15,16,17}$

\section{RESEARCH}

The benefits of prehospital care never have been demonstrated scientifically in many medical and surgical conditions. The time has come to prove the value of field care and determine the most cost-effective and medically sound treatments. ${ }^{33}$

Few investigations have been conducted in out-ofhospital care using controlled, randomized, and prospective study designs. Uncontrolled trials can be misleading and should not be used as a basis for changing treatment. ${ }^{34}$ It is only through randomized, controlled trials and evidence-based decision making that new treatments can be adequately and objectively evaluated. ${ }^{35} \mathrm{~A}$ review of 5,842 EMS-related research articles published within the past 13 years revealed that fewer than $1 \%(n=54)$ were randomized, controlled trials. ${ }^{36} \mathrm{~A}$ major focus of EMS research should be evidencedbased, using well-designed, randomized, controlled trials. Without such proof of effectiveness, the very existence of EMS is open to challenge, and field therapies are arguably unjustified. 
However, in order to address cost-effectiveness and patient outcomes, certain aspects of EMS research have shifted from patient-oriented to systems-oriented research. The systems-based research model is unfamiliar to most physicians. Most physicians have been trained almost exclusively in component-based research, where a single therapeutic intervention for a specific disease is studied in a carefully controlled clinical setting, or in which a single component of a system is tested. This model serves poorly in EMS (and EM) due to an inability to control such a complex environment.

Unique aspects of systems-based problems, such as resource utilization and prevention, have been infrequently investigated. However, there has been a recent and welcomed shift from the traditional quality assurance model, often referred to as the "bad apples" model, to a model based on improving the performance of the entire system, not just that of the underachievers. Dividing the assessment of quality into three components, each of which affects the others, will enhance the understanding of systematic quality improvement. ${ }^{37}$

The first component is structure, encompassing the organization of the health care delivery systems, and the various physical components, such as ambulances, dispatch facilities, and personnel. While research has examined the structure of EMS, most has centered on specific components of a system, studying them in isolation.

The second component is process, or how care is delivered. A simple example is the time line of events as they unfold in the field. EMS researchers have only recently begun temporal-spatial and fine-motion studies that industry has used for decades. There are still serious gaps in our knowledge of out-of-hospital event sequences and times. ${ }^{38}$ Standardized definitions have been proposed with the Utstein Conference in $1991^{39}$ and the NHTSA Uniform Data Set Conference of $1993 .{ }^{19}$ Standardization will enable EMS researchers to more reliably compare geographically distinct systems.

The third component is outcome. From a systems standpoint, outcome refers to the effects of health care delivery on the health status of patients and of populations. ${ }^{40}$ The outcomes-research paradigm is one of the most important trends in medical research in the past five years. For most EPs and EMS physicians, an evidence-based approach has becoming the litmus test for new therapy. Much of clinical research has used the randomized trial, case-control, or cohort study design, which provides information about the efficacy of a treatment, but gives little information on efficacy and cost-effectiveness. Investigators must evaluate the level of benefit expected when average practitioners render services to typical patients under normal circumstances. The systems-based model of research, which operates in the complex uncontrolled field environment, is more useful here than the component-based model.

The goal of outcomes research is to evaluate the value versus harm of specific medical practices. The allocation of increasingly scarce health care resources in the future will favor investigators who strive to shape health care policy and economic decisions using outcome data. Health status assessment, as it refers to various physical, mental, and social measures of health, will become a crucial outcome measurement. EMS investigators have traditionally looked at measures such as resuscitation, mortality, outcome surrogates (admission vs ED discharge), or subjective measures such as the paramedic's assessment of changes in the patient's condition after treatment. EMS needs to keep pace with all medical disciplines and develop models to examine severity of illness, morbidity, and quality-of-life measures. Long-term outcomes, such as need for rehabilitation or return to daily activities or work, are important, particularly when assessing EMS as part of the overall health care system.

Perhaps the main benefit of EMS to the public relates to fear and vulnerability, factors that are seldom measured. EMS can resolve fear for the lay public by its mere arrival. Anxiety is markedly diminished once EMS is at the scene, regardless of level of training or scope of practice. Preparedness is a tangible asset for EMS, and is every bit as valuable as successful resuscitations and lives saved.

In order to carry out these various research agendas, it is imperative that EMS investigators receive enough protected time to enable them to become proficient in the complex process of research. The current economic situation demands that EMS physicians, along with the rest of organized medicine, monitor evolving health care reform initiatives. Comparative research of EMS health care delivery, and the role of the medical transport system, may help to position EMS to succeed in whatever model eventually emerges from the reform effort. Academicians focused on EMS should receive the same departmental support from the chair and research director as any other department member performing research.

Forums for publication and presentation of research are also very important. Fortunately, the major EM journals publish high-quality EMS research. Dedicated journals such as Prehospital Emergency Care, provider-oriented journals such as JEMS and Emergency Medical Services, and newsletters from various professional organizations publish research, concept papers, editorial opinions, and policy updates. EMS physicians 
must be active in the editorial processes of these publications, and ensure that the published EMS literature is of the highest quality. Organizations whose meetings currently support EMS presentations should be expanded, and those that do not presently include EMS should be encouraged to do so.

\section{EMS AND PRIMARY CARE}

The multifaceted role that EMS serves in the community health care system has been recently highlighted. Particular attention has focused on the entry of EMS into what has traditionally been classified as primary care, which includes minor and ambulatory care, health maintenance, and preventive medicine. Pilot projects have been started in several localities and a growing discussion is recorded in the EMS literature. ${ }^{41}$ Programs involve training traditional emergency medical technicians to assume new medical responsibilities of primary care, such as creating expanded scope of practice for EMS providers.

Proponents argue that many patients can be safely managed in the home or workplace without the need for an on-site physician or nurse. ${ }^{42} \mathrm{Un}$ necessary EMS transports, and the resulting ED visits, would be reduced or eliminated, making effective primary care very attractive from a costbenefit standpoint. Supporters also argue that EMS systems with a well-developed infrastructure of trained technicians, vehicles, logistics, training, and communications are well poised to assume additional responsibility.

Projects have ranged from increased responsibility during interfacility transports to proposals for statewide implementation of childhood immunizations and community health. ${ }^{43-45}$ An innovative project in Fort Worth links an ambulance service to a managed care organization. ${ }^{40}$ Providers respond to enrollees' requests for emergency assistance in the usual fashion. Once on the scene, however, patients are evaluated for the appropriateness of treatment options other than transport to the ED, such as to treat and release, or transport to a physician office.

Critics point out that in some locations, EMS is struggling just to meet its traditional mandate, making added responsibility impractical. Urban and rural areas are touted as prime sites for projects because of underserved populations and limited access to primary care. However, these are the same environments suffering from overburdened and underfunded EMS systems, which already suffer staffing and training difficulties. Furthermore, opponents argue that many proposals are redundant because they mimic existing public health and visiting nurse systems. ${ }^{46}$ They argue that a new level of provider may exacerbate health care fragmentation and degrade rather than enhance primary care.

As it exists now, the concept of expanded scope suffers from several deficiencies, including lack of a clearly defined scope of practice and matching curriculum. ${ }^{47,48}$ Expanded scope of practice is a concept whose effectiveness, efficiency, and safety have not been defined. A peer-reviewed body of literature has not had time to develop, and legal precedents are scarce or not directly applicable. ${ }^{49}$ The leadership role of physicians in expandedscope EMS has not been established, nor has there been integration with the rest of the health care resources in the systems studied. ${ }^{50-53}$ For instance, interactions between EMS and physician assistants or nurse practitioners remain to be defined. ${ }^{54}$ Prospective, methodologically sound EMS systems research is sorely needed to explore, direct, and justify expanded scope of practice. ${ }^{55}$ Without a rigorous examination of EMS system redesign, forces other than improved effectiveness and efficiency may detrimentally shape the future, with little hope of reconciliation. ${ }^{56}$

\section{CONCLUSIONS}

By playing an enormous role in patient delivery to the hospital, EMS has become a vital component of EM. Health care reform, however, is taking a serious look at the way that EMS operates, with an eye toward cost containment and efficient resource utilization. Within the fundamental need to contain cost and eliminate waste in health care, there exists an opportunity to improve care. It is vital that physicians explore these new opportunities with a vested interest in EMS. The membership of SAEM should strive to attain the following goals:

- Promote the seamless integration of EMS into all aspects of health care, which affords tremendous opportunities to explore a role for EMS in primary care, preventive medicine, public health, and rehabilitation.

- Take a multidisciplinary approach to integrating EMS into health care in the future. There should be extensive coordination in organizing, planning, implementing, and overseeing all aspects of the system.

- Have universal access to out-of-hospital care as a goal. Financial deterrents to accessing EMS for appropriate care are to be eliminated.

- Recognize that medical direction is essential to the proper functioning of EMS. Responsibility should be delineated, with provision of adequate resources.

- Cultivate medical leadership by developing a 
model EMS fellowship curriculum that incorporates training in administration.

- Identify the educational needs of the public, EMS providers, medical students, EM residents, EPs, nurses, and physicians in other specialties so that model curricula may be developed.

- Conduct research in resource utilization, clinical outcomes, new technology, and cost-effectiveness, for which there is an enormous need.

- Explore avenues for securing adequate operating and research funding.

- Define the role of EMS in primary care as health care payers seek alternate means of providing care using mid-level practitioners.

\section{$\underline{\text { References }}$}

1. The White House Domestic Policy Council. The President's Health Security Plan: The Clinton Blueprint. New York: Random House, 1993.

2. Dionne EJ, Hacker JS. Health care reform is dead-long live health care reform. Ann Emerg Med. 1997; 30:742-5.

3. Koenig KL, Salvucci AA, Zachariah BS, O'Connor RE. EMS systems and managed care integration. Prehosp Emerg Care. 1998; $2: 67-9$.

4. Dickinson E, Verdile VP. Managed care organizations: a link in the chain of survival. Ann Emerg Med. 1996; 28:719-21.

5. Gerson LW, Schelbe DT, Wilson JE. Using paramedics to identify at-risk elderly. Ann Emerg Med. 1992; 21:688-91.

6. Hsaio AK, Hedges JR. Role of the emergency medical services system in region wide health monitoring and referral. Ann Emerg Med. 1993; 22:1696-702.

7. Koenig KL. Unscheduled access to health care: reengineering the 911 system. Acad Emerg Med. 1996; 3:989-91.

8. Billittier AJ, Moscati R, Janicke D, Lerner EB, Seymour J, Olsson D. A multi-site survey of factors contributing to medically unnecessary ambulance transports. Acad Emerg Med. 1996; 3:1046-52.

9. Lombardi G, Gallagher EJ, Gennis P. Outcome of out-ofhospital cardiac arrest in New York City: the pre-hospital arrest survival evaluation (PHASE) study. JAMA. 1994; 271: 678-83.

10. Guly UM, Mitchell RG, Cook R, Steedman DJ, Robertson CE. Paramedics and technicians are equally successful at managing cardiac arrest outside the hospital. BMJ. 1995; 310: $1091-4$.

11. Demetriades D, Chan L, Cornwell E, et al. Paramedic vs. private transportation of trauma patients: effect on outcome. Arch Surg. 1996; 131:133-8.

12. Davidson SJ, Sturgill TD. Carpe diem-appointed care. Acad Emerg Med. 1996; 3:655-6.

13. Swor RA. Funding strategies. In: Kuehl AE (ed). Prehospital Systems and Medical Oversight, 2nd ed. St. Louis: Mosby-Year Book, 1994, pp 76-80.

14. Stout JL. System financing. In: Roush WR (ed). Principles of EMS Systems. Dallas: 1994, pp 451-73.

15. Schneider SM, Cobaugh DJ, Leahey NF. Gatekeepers: a missed opportunity for safe transport. Acad Emerg Med. 1998; 5:587-92.

16. Clawson JJ. Emergency medical dispatch. In: Kuehl AE (ed). Prehospital Systems and Medical Oversight, 2nd ed. St. Louis: Mosby-Year Book, 1994, pp 125-52.

17. Clawson JJ. Emergency medical dispatch. In: Roush WR (ed). Principles of EMS Systems. Dallas: American College of Emergency Physicians, 1994, pp 263-89.

18. Snyder JA, Baren JM, Ryan SD, Chew JL, Seidel JS. Emergency medical service system development: results of the statewide emergency medical service technical assistance program. Ann Emerg Med. 1995; 25:768-75.

19. Spaite D, Benoit R, Brown $D$, et al. Uniform prehospital data elements and definitions: a report from the Uniform Pre hospital Emergency Medical Services Data Conference. Ann Emerg Med. 1995; 25:525-34.

20. Garrison HG, Foltin GL, Becker LR, et al. The role of emergency medical services in primary injury prevention. Prehospital Emergency Care. 1997; 1:156-62.

21. Harrawood D, Gunderson MR, Fravel S, Cartwright K, Ryan JL. Drowning prevention: a case study in EMS epidemiology. J Emerg Med Serv. 1994; 19(6):34-41.

22. Ogden JR, Criss EA, Spaite DW, Valenzuela TD. The impact of an EMS-initiated, community-based drowning prevention coalition on submersion deaths in a southwestern metropolitan area [abstract]. Acad Emerg Med. 1994; 1(2):A101.

23. American College of Emergency Physicians, American Board of Emergency Medicine, and Society for Academic Emergency Medicine. Core content for emergency medicine. Ann Emerg Med. 1991; 20:920-34.

24. Cone DC, Davidson SJ. Survey of emergency medical services curricula in U.S. emergency medicine residencies. Acad Emerg Med. 1995; 2:1109-12.

25. Verdile VP, Krohmer JR, Swor RA, Spaite DW. Model curriculum in emergency medical services for emergency medicine residency programs. Acad Emerg Med. 1996; 3:716-22.

26. Norton EG. Model curriculum in air medical transport services for emergency medicine residencies. Ann Emerg Med. 1991; 20:431-2.

27. Krohmer JR, Swor RA, Benson N, Meador SA, Davidson SJ. Prototype curriculum for a fellowship in emergency medical services. Prehosp Disaster Med. 1994; 9:73-7.

28. Mattox KL, Bickell W, Pepe PE, et al. Prospective MAST study in 911 patients. J Trauma. 1989; 29:1104-12.

29. Brown CG, Martin DR, Pepe PE, et al. Standard versus high-dose epinephrine in out-of-hospital cardiac arrest: a controlled clinical trial. N Engl J Med. 1992; 327:1051-5.

30. Bickell WH, Wall MJ, Pepe PE, et al. Immediate versus delayed fluid resuscitation for hypotensive patients with penetrating torso injury. N Engl J Med. 1994; 331:1105-9.

31. Pellicci M, Halogen L, Dhindsa H. Out-of-hospital experience with the syringe esophageal detector device. Acad Emerg Med. 1997; 4:563-8.

32. Jenkins WA, Verdile VP, Paris PM. The syringe aspiration technique to verify endotracheal tube position. Am J Emerg Med. 1994; 12:413-6.

33. Stapczynski JS. Conducting prehospital research. In: Roush WR (ed). Principles of EMS Systems. Dallas: American College of Emergency Physicians, 1993.

34. Colditz G, Miller J, Mosteller J. How study design affects outcome in comparisons of therapy I. Med Stat Med. 1989; 8: $441-54$.

35. Schultz KF, Chalmers I, Hayes RJ, et al. Empirical evidence of bias: dimensions of methodological quality associated with estimates of treatment effects in controlled trials. JAMA. 1995; 273:408-12.

36. Callaham M. Quantifying the scanty science of prehospital emergency care. Ann Emerg Med. 1997; 30:785-90.

37. Donabedian A. The quality of care, how can it be assessed? JAMA. 1988; 260:1743-8.

38. Mosesso VN Jr. The most neglected tool in EMS: the clock. Ann Emerg Med. 1993; 22:88-9.

39. Cummins RO, Chamberlain DA, Abramson NS: Recommended guidelines for uniform reporting of data from out-ofhospital cardiac arrest. Ann Emerg Med. 1991; 20:861-74.

40. Dart RC, Whitley TW, Cordell WH. Outcomes research: importance for emergency physicians. In: Academic News and Views, The Newsletter of the ACEP Academic Affairs Committee. Dallas: American College of Emergency Physicians, 1995, pp 1-2.

41. Garza MA. Rethinking EMS. After Sand Key, things will never be the same . . . EMS Primary Care Conference. J Emerg Med Serv. 1994; 19(5):103-7.

42. Brown WE Jr. How about physician extenders? [editorial]. J Emerg Med Serv. 1993; 18( ):7-8.

43. Garza MA. Paramedics: the next generation. Paramedic extended scope of practice programs. J Emerg Med Serv. 1993; 18(8):89-94,96.

44. Garza MA. Florida and Texas expand expanded scope projects. J Emerg Med Serv. 1994; 19(10):79-81.

45. Kuhr S. Redesigning our future: a forum. Focusing the expanded scope [editorial]. J Emerg Med Serv. 1995; 20(1):129- 
32.

46. Robinson K. Keeping the emergency in EMS: a cautious look at out-of hospital primary care [letter]. J Emerg Nurs. 1994; 20(suppl):30A-32A.

47. Garza MA. Treatment without transport. Expanded scope concept gains momentum. J Emerg Med Serv. 1994; 19(4): $75-7$.

48. EMS Primary Care Conference and Summit: "The Sand Key Conference," Summit Report. Sacramento, CA: Executive Management Services, 1994.

49. Criss E. Unlock the future: EMS must choose a path [editorial]. J Emerg Med Serv. 1994; 19(12):23-4.

50. Knezevich BA, Mallot LF. The nurse's role in EMS. Emerg Med Serv. 1982; 11(Jan-Feb):72.

51. Ampolsk AG. Prehospital RNs. Emergency. 1989; 21:32-
5.

52. Lyle NA. Prehospital nurse clinician: job description and evaluation tool. J Emerg Nurs. 1986; 12:365-9.

53. Palmer CE, Gonsoulin SM. Nurse-paramedic interactions: teamwork or turf wars? Prehosp Disaster Med. 1992; 7: $45-50$.

54. Lenehan GP. Timing is everything: the growing need for emergency nurse practitioners [editorial]. J Emerg Nurs. 1993; 19:269-70

55. Spaite DW, Criss EA, Valenzuela TD, Meislin HW. Developing a foundation for the evaluation of expanded-scope EMS: a window of opportunity that cannot be ignored. Ann Emerg Med. 1997; 30:791-6.

56. Neely KW, Drake MER, Moorhead JC, et al. Multiple options and unique pathways: a new direction for EMS? Ann Emerg Med. 1997; 30:797-9.

\section{REFLECTIONS Opening Exchanges}

Long fatigued by repetitive introductions I slipped late evening into the doorway To hear, "Oh there's the doctor!"

I cringed, knowing our collective delay. A three-year-old boy, cc: foot injury Rested anxiously on a nurturing lap.

His angry, dependent shoeless extremity

And feared expression clarified his mom's concern.

My eye caught a limp yellow companion

Silented by a timeworn grasp of its neck.

Its avian limb pyramided on yet another lap.

My lead, "Who did you bring with you?"

"Duck," he replied quite naturally.

"Is that a small case 'd,' or are we talking proper noun?"

“This is capital 'D,' Duck," mom enjoined.

"Oh no," he corrected, "this is 'Ducky Wucky.”

Now I ask you all out there,

"How can you not love to care for kids?"

JONATHAN I. SINGER, MD

Department of Emergency Medicine

Wright State University

Dayton, Ohio 